\title{
GURU PROFESIONAL ADALAH KUNCI MEWUJUDKAN PENDIDIKAN BERKUALITAS
}

\author{
Nana Sepriyanti \\ Dosen Fakultas Tarbiyah IAIN Imam Bonjol Padang \\ e-mail: nana_sepriyanti@gmail.com
}

\begin{abstract}
The keyword to achieve quality education is depend on profesional teacher in their fields, therefore there should be a concrete step in an effort to lift the image of the teacher profession as an honorable profession, so that teachers can work as much as possible in building a quality education. Professional responsibility of teachers is not fragmentary, but with entirely, completely, as much as possible from upstream to downstream. All thing are not only teacher responsibility of the students or schools, but will be fully responsible to Allah SWT.
\end{abstract}

\begin{abstract}
Abstrak: Kata kunci untuk kualitas pendidikan tergantung kepada guru yang profesional di bidangnya karena itu harus ada langkah yang konkret untuk mempertahankan pandangan bahwa guru adalah profesi terhormat, sehingga guru dapat bekerja keras dalam membangun kualitas pendidikan. Tanggung jawab profesional bukanlah hal yang terpisah tetapi merupakan satu kesatuan yang utuh dari tingkat atas ke bawah. Semuanya bukan hanya tanggung jawab guru kepada siswa dan sekolah tapi juga tanggung jawab moril kepada Allah SWT.
\end{abstract}

Kata Kunci: Guru profesional, pendidikan berkualitas

\section{PENDAHULUAN}

Sesuai dengan UU. No. 20 th. 2003 tentang Sistem Pendidikan Nasional, ditegaskan bahwa guru/dosen memiliki tugas utama membimbing, mengajar, dan melatih peserta didik secara profesional, sehingga dapat mengantarkan peserta didiknya mencapai tujuan pendidikan. Pada pasal 39 UU Sisdiknas tahun 2003 juga ditegaskan, bahwa pendidik merupakan tenaga profesionl yang bertugas merencanakan dan melaksanakan proses pembelajaran, menilai hasil pembelajaran, melakukan bimbingan dan pelatihan, setta melakukan penelitian dan pengabdian kepada masyarakat, terutama bagi pendidik pada perguruan tinggi.

Berdasarkan amanah undang-undang diatas, dipahami bahwa peran dan tanggung jawab sebagai tenaga pendidik apakah guru, dosen dsb tidaklah ringan atau dianggap enteng dipandang sebelah mata Pendidikan harus ditangani oleh orang-orang yang mengerti dengan ilmu pendidikan dan profesional di bidangnya.

Adalah wajar jika ranking mutu atau kualitas pendidikan Indonesia tidak pernah beranjak naik tetap saja berada di bawah Malaysia dan Vietnam, pada sisi lain permasalahan korupsi juga semakin menjadijadi, korupsi tidak hanya di kalangan generasi tua melainkan generasi muda pun juga sudah berpenyakit yang sama, temuan terbaru mengungkapkan bahwa puluhan PNS muda memiliki rekening milyaran rupiah, selain itu banyak orang yang tidak merasa bersalah berlaku tidak benar, berbagai argumen mereka lakukan demi menutupi kebohongan. Hal demikian adalah pertanda pendidikan berkualitas masih jauh dari harapan, padahal pendidikan berkualitaslah sebagai satu-satunya yang dapat membentuk manusia berkarakter cerdas dan memuliakan kemanusiaannya. 
Negara-negara maju sangat mengedepankan aspek profesional dalam mengelola apapun, apalagi dalam mengelola pendidikan, guru yang profesional sangat menentukan kemana arah pendidikan maupun masa depan suatu bangsa. Kualitas suatu bangsa sangat ditentukan oleh kualitas pendidikan bangsa itu sendiri. Dalam tulisan singkat ini penulis akan mencoba membahas guru profesional adalah kunci mewujudkan pendidikan berkualitas.

\section{PEMBAHASAN}

\section{Guru sebagai Pendidik Profesional}

Guru sebagai tenaga pendidik dalam menyelenggarakan pendidikan, profesi guru telah mendapat pengakuan oleh UndangUndang Sisdiknas No 20/2003 yang menyatakan bahwa:"Pendidik adalah tenaga kependidikan yang berkualifikasi sebagai guru, dosen, konselor, pamong belajar, widyaiswara, tutor, instruktur, fasilitator, dan sebutan lain yang sesuai dengan kekhususannya serta berpartisipasi dalam menyelenggarakan pendidikan.

Dalam Dictionary of Education dinyatakan bahwa teacher is (1) a person employed in an official capacity for purpose of guiding and directing the learning experiences of pupil in an education institution, wether public or private, (2) a person who because of rich or unusual experiences or education or borh in given field is able to contribute to the growth and development of other person who come in contrac with him. (3) a person who has cmpleted a professional curriculum in a teacher education institutin and whose training has been officially recognized by award of an appropriate teaching sertificate, (4) a person who instructur. Menurut Kamus Besar Bahasa Indonesia guru adalah orang yang pekerjaannya(mata Pencahariannya, profesinya) mengajar(moeliono, 1988:288). Dalam UU Sisdiknas No 20 tahun 2003 pasal 39 ditegaskan lagi bahwa Pendidik merupakan tenaga profesional yang bertugas merencanakan dan melaksanakan proses pembelajaran, menilai hasil pembelajaran, melakukan pembimbingan dan pelatihan, serta melakukan penelitian dan pengabdian kepada masyarakat, terutama bagi pendidik pada perguruan tinggi.

Dari uraian di atas dipahami bahwa guru bukan hanya seseorang yang menjajakan materi pelajaran di depan kelas, bukan sekedar transfer of knowledg, melainkan tugas utama adalah sebagai pendidik profesional yang mampu memuliakan kemanusian manusia sesuai dengan kaidah ilmu pendidikan.

Kaidah ilmu pendidikan yang harus dipahami guru sebagai tenaga pendidik agar memiliki arah yang jelas dalam mengelola pendidikan adalah Harkat dan Martabat Manusia (HMM). Menurut Prayitno (2009: 14) ada tiga komponen HMM yang perlu dipihami tersebut.Komponen pertama adalah tentang hakekat manusia yang meliputi: (1) makhluk yang beriman dan bertakwa kepada Tuhan Yang Maha Esa, (2) makhluk yang paling indah dan sempurna dalam pencitraannya, (3) makhluk yang paling tinggi derajatnya (4), khalifah di muka bumi, dan (5) pemilik hak-hak asasi manusia.

Lebih jauh Prayitno (2009: 15) menyatakan bahwa untuk pengembangan diri dan kehidupan manusia selanjutnya, dia dilengkapi dengan dimensi-dimensi kemanusiaan, yang meliputi: 1) dimensi kefitrahan, 2) dimensi keindividualan, 3) dimensi kesosialan, 4) dimensi kesusilaan, dan 5) dimensi keberagamaan.

Prayitno (2009: 19) juga menyatakan bahwa untuk memungkinkan perkembangan individu ke arah "manusia seutuhnya", manusia dikarunia oleh Sang Maha Pencipta lima jenis bibit pengembangan, yang disebut panca daya, yang meliputi: 1) daya taqwa, 2) daya cipta, 3) daya karsa, 4) daya rasa, dan 5) daya karya.

Suriasumantri (2003: 39) berpendapat bahwa "manusia adalah satu-satunya makhluk yang mengembangkan pengetahuan ini secara sungguh-sungguh."

Dari pendapat di atas terlihat bahwa pada Suhartono (2006, h. 52) menyatakan dalam konteks pendidikan manusia adalah makhluk yang selalu memerankan diri sebagai subjek dan objek 
Senada dengan apa yang dikemukakan oleh Suhartono, Syam (1986: 153) menyatakan

Manusia adalah subyek pendidikan selaligus obyek pendidikan. Manusia dewasa yang berkebudayaan adalah subyek pendidikandalam arti yang bertanggung jawab menyelenggarakan pendidikan. Manusia yang belum dewasa dalam proses perkembangan kepribadiannya baik menuju pembudayaan maupun proses kematangan integritas adalah "obyek" pendidikan. Artinya, mereka adalah sasaran atau "bahan" yang dibina.

Dari pendapat di atas terlihat bahwa pada hakekatnya manusia adalah makhluk yang diberi sejumlah potensi oleh Alah Tuhan Yang Maha Esa untuk dikembangkan sedemikian rupa sehingga manusia bisa menjadi khalifah di muka bumi karena manusia adalah makhluk yang paling tinggi derajatnya dengan berbagai hak asasi yang dimilikinya yang tidak dimiliki oleh makhluk lainnya.

Kaidah keilmuan di atas dipahami bahwa pada hakekatnya manusia adalah makhluk yang telah diberi akal oleh Allah Tuhan YME, sehingga dengan akalnya dia akan bisa mengembangkan pengetahuan di muka bumi ini. Dengan kata lain, manusia pada hakekatnya adalah makhluk yang diamanahkan Allah untuk menyelenggarakan pendidikan dengan sungguh-sungguh. Semakin bagus kualitas pendidikan yang diselenggarakan tentu akan mampu mengembangkan segenap potensi yang Tuhan berikan, dan pada akhirnya akan memberikan kesejahteraan terhadap keberlangsungan hidup manusia itu sendiri.

\section{Pendidikan, Hakikatnya dan Tujuannya}

Menurut Prayitno (2008: 45), pendidikan adalah upaya memuliakan kemanusiaan manusia untuk mengisi dimensi kemanusiaan melalui pengembangan panca daya secara optimal dalam rangka mewujudkan jati diri manusia sepenuhnya. Panca daya dimaksud meliputi daya taqwa, daya cipta, daya karsa, daya rasa, dan daya karya. Jadi, walaupun pendidikan itu bermacam-macam tetapi satu, yaitu upaya memuliakan kemanusiaan manusia"

Definisi di atas dipahami bahwa melalui pendidikan harkat dan martabat seseorang akan bisa berkembang dan diangkat sehingga ia bisa menjadi khalifah di muka bumi ini sebagaimana yang diyakini oleh setiap manusia yang mengaku dirinya Islam. Melalui pendidikan, seseorang akan bisa mengembangkan daya takkwanya kepada sang Pencipta, dengan mengerjakan semua perintah dan menjauhi semua larangan-Nya. Melalui pendidikan seseorang akan bisa mengembangkan daya ciptanya dengan memanfaatkan akal nya. Dengan pendidikan kekuatan rasa (afektif) nyakan bisa dikembangkan. Dengan pendidikan daya karsa seseorang akan bisa dikembangkan untuk bisa mencapai kondisi yang lebih baik dari yang sebelumnya. Dengan pendidikan daya karyanya juga akan berkembang sehingga apa-apa yang dia hasilkan bisa bermanfaat baik bagi dirinya sendiri, orang lain, maupun bagi lingkungan.nya. Tidak mengherankan jika melalui pendidikan, manusia bisa menjadi khalifah bagi dirinya sendiri, bagi keluarga, kelompok, masyarakat, bangsa, bahkan umat manusia dan lingkungannya karena dengan pendidikan dia bisa senantiasa menjalin hubungan vertikal dengan sang Khalik, dan menjaga hubungan horizontal dengan sesama makhluk Allah, dan senantiasa menjaga lingkungannya.

Tidak jauh berbeda dengan apa yang disampaikan Prayitno, Danim (2003: 4) menyatakan "agenda utama pendidikan adalah proses memanusiakan manusia menjadi manusia. Proses itulah yang disebut dengan pemanusiaan, proses membentuk manusia menjadi insan sejati.

Pada dasarnya sejak lahir anak manusia itu sudah manusia. Tetapi harkat dan martabatnyalah yang belum dihargai dan dimuliakan dan dimanusiakan. Oleh sebab itu pendidikan harus mengangkat harkat dan martabat manusia (memuliakan manusia) atau memanusiakan manusia. . 
Dengan kata lain, pendidikan akan menjadikan manusia menjadi manusia sejati yaitu manusia yang bisa menjadi khalifah di muka bumi, menjaga kelestarian alam, berbuat baik kepada sesama dan menjadi makhluk yang hidup tidak hanya untuk tujuan kesejahteraan di dunia, tetapi juga di akhirat.

Dari pengertian pendidikan sebagaimana yang telah disebutkan di atas pada dasarnya sudah tergambar apa yang menjadi tujuan pendidikan. Tetapi secara eksplisit sejumlah pakarpun telah mengemukakan tujuan pendidikan. Untuk mendapatkan gambaran tentang tujuan pendidikan, maka pada bagian berikut ini penulis akan mengemukakan tujuan pendidikan menurut sejumlah pakar.

Dalam Undang-undang RI No. 20 Tahun 2003 Bab II Pasal 3 dinyatakan:

Pendidikan nasional berfungsi mengembangkan kemampuan dan membentuk watak serta peradaban bangsa yang bermartabat dalam rangka mencerdaskan kehidupan bangsa, bertujuan untuk berkembangnya potensi peserta didik agar menjadi manusia yang beriman dan bertakwa kepada Tuhan Yang Maha Esa, berakhlak mulia, sehat, berilmu, cakap, kreatif, mandiri, dan menjadi warga Negara yang demokratis serta bertanggung jawab.

Berkaitan dengan tujuan pendidikan, Mulyasa (2004: 21) menyatakan:

Secara mikro pendidikan nasional bertujuan membentuk manusia yang beriman dan bertakwa kepada Tuhan Yang Maha Esa, beretika (beradab dan berwawasan budaya bangsa Indonesia), memiliki nalar (maju, cakap, cerdas, kreatif, inovatif dan bertanggung jawab), berkemampuan komunikasi sosial (tertib dan sadar hukum, kooperatif dan kompetitif, demokratis), dan berbadan sehat sehingga menjadi manusia mandiri.

Lebih jauh Ali (1990: 87) menyatakan: Pendidikan kita bertujuan untuk meningkatkan ketakwaan terhadap Tuhan Yang Maha Esa, kecerdasan dan keterampilan, mempertinggi budi pekerti, memperkuat kepribadian dan mempertebal semangat kebangsaan dan cinta tanah air, agar dapat menumbuhkan manusia-manusia pembangunan yang dapat membangun dirinya sendiri serta bersama-sama bertanggung jawab atas pembangunan bangsa.

Sementara itu Crijn dan Reksosiswojo dalam Jalaluddin dan Said (1994:39) menyatakan: "Tujuan pendidikan adalah agar anak terbentuk kata hatinya". Suhartono (2006:31) lebih jauh mengatakan: Pendidikan tidak cukup hanya dipelajari secara ilmiah teoritis dengan sasaran kecerdasan intelektual saja. .Nilainilai hakiki pendidikan seharusnya dipelajari secara saksama dengan sasaran kecerdasan spiritual, untuk kemudian dikembangkan di dalam keseharian kehidupan bermasyarakat dengan sasaran kongkret berupa kecerdasan emosional.

Sementara itu Jalaluddin dan Said (1994: 39) menyatakan:“Tujuan pendidikan Islam adalah kesejahteraan hidup di dunia dan di akhirat."

Tilaar (2004: 54) yang menyatakan: Tujuan pendidikan bukan hanya manusia yang cerdas di dalam arti menguasai kecerdasan akademik tetapi yang terpenting ialah ia haruslah manusia yang berbudaya. Yang kita perlukan bukan hanya educated human being tetapi educated and civilized human being yang cerdas dan beradab.

Lebih tegas Prayitno (2009: 44) bahwa tujuan pendidikan pada dasarnya tidak lain adalah arah yang hendak dicapai demi terwujudnya tujuan hidup manusia, yaitu hidup sesuai HMM, dengan segenap kandungannya, yaitu berkembang secara optimal hakikat manusia, dimensi kemanusiaan dan pancadaya. Tujuan pendidikan mengarah pada pembetukan yang berperikehidupan taqwa kepada Tuhan Yang Maha Kuasa, sesuai dengan keindahan, kesempurnaan dan ketinggian derajatnya, menguasai dan memelihara alam tempat tinggalnya dan terpenuhi hakhak asasinya. 
Dari berbagai tujuan yang telah dikemukakan dapat sekali lagi disimpulkan bahwa tujuan pendidikan pada dasarnya adalah menjadikan manusia menjadi manusia seutuhnya yaitu manusia yang bisa bekerja sama dengan orang lain, hidup tidak hanya untuk kepentingan dirinya saja tetapi untuk seluruh makhluk yang ada di muka bumi, untuk menjaga kelestarian alam sehingga dia bisa mendapatkan kebahagiaan di dunia dan di akhirat. Melalui pendidikan akan terbentuk keselarasan antara ketiga kecerdasan intelektual, emosional, dan spiritual, sehingga kita akan bisa sukses menjalin hubungan dengan sang Khalik, sesama manusia dan dengan makluk lainnya, serta berupaya menjaga kelestarian lingkungan hidup kita agar tercapainya kesejahteraan hidup di dunia dan di akhirat. .

\section{Guru Profesional dan Pendidikan Berkualitas}

Dewasa ini penyelenggaraan pendidikan di indonesia telah mulai memasuki era profesional. Hal ini ditandai oleh penegasan bahwa "pendidik merupakan tenaga profesional" (UU No.20 Tahun 2003 Pasal 39 ayat 2), dan pada UU No. 14 tahun 2005 dijelaskan lagi bahwa"Profesional adalah pekerjaan atau kegiatan yang dilakukan seseorang dan menjadi sumber penghasilan kehidupan yang memerlukan keahlian, kemahiran, atau kecakapan yang memenuhi standar mutu atau norma tertentu serta memerlukan pendidikan profesi. Pada pasal di atas memberikan pemahaman bahwa di dalam konsep profesional terkandung hal-hal berikut:

a. Suatu pekerjaan atau kegiatan

b. Menjadi sumber penghasilan untuk kehidupan

c. Memerlukan keahlian, kemahiran atau kecakapan

d. Memenuhi standar mutu atau norma tertentu

e. Memerlukan pendidikan profesi

Dengan kandungan profesi demikian

itu, suatu profesi harus benar-benar dipersiapkan dan dibina dengan sebaikbaiknya, dalam hal ini melalui pendidikan profesi dan sarana pembinaan lainnya, sehingga menjadi profesi yang benar-benar berkualitas dalam meningkatkan mutu pendidikan. Untuk menjadi profesional dalam bidang apapun menurut Prayitno (2010), seseorang harus menguasai dan memenuhi unsur trilogi profesi, yaitu: (1) komponen dasar keilmuan, (2) komponen substansi profesi dan (3) komponen praktik profesi.

Sebagai profesi pendidik komponen dasar keilmuan yang perlu dimiliki adalah ilmu pendidikan, komponen substansi profesi adalah belajar dan pembelajaran, dengan substansi pendidikan, sedangkan komponen praktik profesi adalah praktik pembelajaran dengan substansi pendidikan.

Komponen dasar keilmuan menyiapkan (calon) tenaga profesional dengan landasan dan arah tentang wawasan, pengetahuan, keterampilan, nilai dan sikap (WPKNS) berkenan dengan profesi yang maksud. Pendidik diwajibkan menguasai Ilmu Pendidikan. Dengan dasar keilmuan inilah pendidik menguasai dengan baik kaidah-kaidah keilmuan pendidikan sebagai dasar memahami peserta didik (sebagai sasaran dalam pelayanan pendidikan) dan memahami seluk-beluk proses pembelajaran yang akan dijalani peserta didik melalui modus pembelajaran tertentu(Prayitno;2011)

Komponen substansi profesi memberikan modal tentang apa yang menjadi fokus dan objek praktik spesifik profesi pendidik dengan bidang khusus kajiannya, pendekatan, aspek-aspek kompe-tensi, sarana operasional dan manajemen, kode etik, serta landasan praktik operasional.

Komponen praktik merupakan realisasi pelaksanaan pelayanan profesi setelah kedua komponen profesi(dasar keilmuan dan substansi profesi )dikuasai. Mutu pelayanan pendidik diukur dari penampilan praktik pelayanan oleh pendidik terhadap sasaran pelayanan.

Ketiga komponen trilogi profesi merupakan satu kesatuan tak terpisahkan, ketiganya merupakan kesatuan, dan dipelajari dengan intensif sehingga menghasilkan keterampilan keahlian yang tinggi atau bahkan sangat tinggi mengacu kepada standar 
norma atau standar mutu tertentu. Penguasaan dan penyelenggaraan trilogi profesi yang dimasudkan itu secara mantap dan konsisten merupakan jaminan bagi suksesnya penampilan profesi demi kebahagiaan sasaran pelayanan.

Apabila ketiga komponen trilogi profesi telah terbina dengan baik dan teraplikasikan di dunia pendidikan, maka guru sebagai suatu profesi semestinyalah akan menajdi profesi bermartabat. Yaitu meliputi kondisi pelayanan bermartabat, karena pelayanan profesional yang dilaksanakan benar-benar bermanfaat bagi kemaslahatan kehidupan secara luas. Ditegaskan oleh Prayitno (2011: 32) bahwa pelayanan yang bermartabat meliputi dua hal:

(1) Pelaksanaan Bermandat, yaitu pelayanan profesional diselenggarakan oleh petugas atau pelaksana yang bermandat

(2) Pengakuan sehat, yaitu pelayanan profesional yang dimaksudkan itu diakui secara sehat oleh pemerintah dan masyarakat.

kondisi:

Kemartabatan profesi meliputi

1. Pelayanan profesional yang diselenggarakan benar-benar bermanfaat bagi kemaslahatan kehidupan secara luas

2. Pelayanan profesional diselenggarakan oleh petugas atau pelaksana yang bermandat

3. Pelayanan profesional yang dimaksudkan itu diakui secara sehat oleh pemerintah dan masyarakat (Prayitno: 2010)

Dengan memperhatikan kualifikasi di atas sangat memugkinkan pendidikan akan terseleggara dengan baik, kecelakaan pendidikan oleh karena banyak pendidik tidak mengeti dengan ilmu pendidikan (PENTIP), jelas akan dapat dihindari, karena pendidik sangat mengerti dan memahami profesi pendidikan itu sesungguhnya. Berarti penyelenggaraaan praktik pendidikan diwarnai oleh pendidik yang mengerti dengan ilmu pendidikan (PENDIP).

Praktik PENTIP seringkali hanya berkutat di muara dari aliran sungai pendidikan tanpa memperhatikan atau tidak peduli apa yang menjadi kondisi di tengah aliran sungai (kajian leilmuan pendidikan dan keprofesionalan pendidik). Pendidik yang benar-benar profesional handal adalah mereka yang telah mengarungi seluruh bagian dari aliran sungai pendidikan dari hulu sampai ke hilir, dari mata air sampai muara dan menagkap secara tepat dan dinamis semua pesan dan pengalaman yang akhirnya ia tumpahkan secara cerdas dalam opersional pendidikan pada satuan-satuan pendidikan sebagai muara dari aliran sungai pendidikan yang berdinamika tanpa henti (Prayitno: 2011).

Pendidik yang mengerti dengan ilmu pendidikan (PENDIP), maka pendidik akan berupaya melaksanakan tugas-tugas yang menjadi profesinya dengan baik. Pekerjaan yang dilaksanakan selalu memperhatikan prinsip BMB3 (berfikir, merasakan, bersikap, bertindak dan bertanggung jawab). BMB3 selalu menggiring guru dalam bertugas tentu guru akan selalu berupaya memberikan pelayanan terbaik dalam proses pembelajaran. Materi maupun penelolaan dan evaluasi pembelajaran benar-benar disiapkan dengan matang,tidak ada istilah asal-asalan sekedar memenuhi kewajiban, sistem kebut semalan, paham atau tidak peserta didik terhadap pelajaran bukanlah persoalan, intinya semua praktik yang tidak betanggung jawab dalam melaksanakan pendidikan berupaya ditekan seminimal mungkin. Dalam istilah manajemen guru profesional sangat memperhatikan prinsip POAC (planning, organizing, actuating dan controlling), semua itu dilaksanakan dengan penuh tanggung jawab. Tidak hanya bertanggung jawab terhadap peserta didik, sekolah, bangsa dan negara, akan tetapi menjadi tanngung jawab utama terhadap Tuhan YME, karena pada komponen hakikat manusia, manusia itu adalah makhluk yang beriman dan bertaqwa kepada Tuhan yang maha Esa.

Sebagai langkah kongkret berikutnya dalam menggapai guru profesional berdasarkan Permendiknas No. 16/2007 pemerintah juga telah menetapkan kualifikasi akademik yang harus dipenuhi oleh seorang guru yaitu pendidikan minimal Diploma IV atau Sarjana (S1). Untuk menindak lanjuti Permen ini sekarang pemerintah selalu 
mendorong agar guru-guru yang belum S1 harus kembali ke kampus untuk melanjutkan pendidikan agar sesuai dengan kualifikasi yang dipersyaratkan.

Di samping itu juga ditetapkan Standar Kompetensi Pendidik, bahwa ada empat kompetensi inti yang dirumuskan sebagai berikut:

a. Kompetensi Pedagogik

b. Kompetensi Kepribadian

c. Kompetensi Sosial

d. Kompetensi Profesional

Bagi guru yang telah memenuhi persyaratan akademik di atas, pemerintah juga telah melakukan prosedur tertentu untuk memperoleh predikat profesional. Prosedur yang telah dan mulai dikembangkan adalah (Prayitno, 2010)

a. Sertifikasi guru, (guru pengampu mata pelajaran dan guru BK) dengan fortofolio.

b. Sertifikasi guru, (guru pengampu mata pelajaran dan guru BK) dengan pola pendidikan dan latihan profesi guru (PLPG/PLPG-BK).

c. Program Pendidikan Profesi, (PPG untuk guru pengampu mata pelajaran dan PPK untk guru BK).

Langkah-langkah yang telah dilakukan di atas, diharapkan profesi pendidik akan menjadi profesi bermartabat, adapun kemartabatan profesi menurut Prayitno antara lain:

1. Bermanfaat, artinya pelayanan pendidikan yang diberikan oleh guru benar-benar dirasakan manfaatnya oleh peserta

2. Bermandat, artinya bahwa yang akan menjadi guru ke depan adalah guru yang memiliki kewenangan dan memperoleh pendidikan secara khusus melalui program pendidikan profesi

3. Diakui secara sehat, artinya pemerintah dan masyarakat mengakui keberadaan dan kebermanfaatan profesi tersebut.

Selanjutnya tentang mutu pendidikan, Sidi (2001: 74-75) menyatakan bahwa upaya peningkatan mutu pendidikan dapat dilakukan melalui langkah-langkah berikut:

1. Pertama, pembenahan kurikulum pendidikan yang dapat memberikan kemampuan dan keterampilan dasar minimal (minimum basic skills), menerapkan konsep belajar tuntas (mastery learning), dan membangkitkan sikap kreatif, inovatif, demokratis dan mandiri bagi para siswa.

2. Kedua, peningkatan kualifikasi, kompetensi dan profesionalisme tenaga kependidikan sesuai dengan kebutuhan mereka melalui pendidikan dan pelatihan, melalui lembaga pendidikan tenaga kependidikan, (LPTK) dan lembaga diklat professional.

3. Ketiga, penetapan standar kelengkapan dan kualitas sarana dan prasarana pendidikan yang menjadi persyaratan bagi setiap lembaga pendidikan dasar dan menengah, sehingga sekolah dapat melaksanakan kegiatan belajar mengajar secara optimal.

4. Keepat, pelaksanaan program peningkatan mutu pendidikan berbasis sekolah (PMPBS) sebagai upaya pemberian otonomi pedagogis kepada guru dan kepala sekolah dalam melaksanakan kegiatan belajar mengajar, sehingga mereka dapat melakukan yang terbaik untuk meningkatkan prestasi siswa dan kinerja sekolah serta dapat bertanggung jawab kepada orang tua dan masyarakat tentang kualitas pembelajaran dan hasil belajar siswa yang dicapai.

5. Kelima, penciptaan iklim dan suasana kompetitif dan koperatif antar sekolah dalam memajukan dan meningkatkan kualitas siswa dan sekolah sesuai dengan standar yang telah ditetapkan.

Jika profesi guru telah benar-benar dirasakan manfaatya oleh peserta didik, praktik pembelajaran telah hijrah dari teching kepada learning, sangat dimungkinkan pembelajaran bermakna dapat dirasakan oleh peserta didik. Seorang guru melakukan pekerjaannya bukan hanya sekedar mencari nafkah lahiriah, akan tetapi didorong oleh rasa cinta, kesetiaan dan tanggung jawab segala pekerjaannya dilakukan untuk sesuatu yang mulia, sesuatu yang luhur dan sesuatu 
yang sejati. (Andreas Harefa dalam Firdaus, 2010)

Keberadaan guru yang diakui dan dihargai oleh pemerintah dan masyarakat, akan mendorong guru untuk bersungguhsungguh memainkan peranannya, segenap energi/kemampuan yang dimiliki pasti akan diberdayagunakan demi terwujudnya kualitas pendidikan semakin baik dimasa mendatang

\section{SIMPULAN}

Pendidikan berkualitas akan dapat menjadi kenyataan, apabila dunia pendidikan ditangani oleh tenaga profesional, terutama oleh guru-guru profesional dan bermartabat. Guruguru profesional inilah yang senantiasa berpijak pada konsep HMM dalam melaksanakan praktik pendidikan. Guru Profesional juga sangat memahami hakikat dan tujuan pendidikan itu sendiri. Guru Profesional akan selalu memperhatikan PENDIP dan terhindar dari PENTIP, karena Pendidikan atau pembelajaran yang dilaksanakan senantiasa memperhatikan prinsip BMB3, mengingat tanggung jawab guru profesional bukanlah sepenggal-sepenggal, melainkan dengan sepenuhnya, seutuhnya, semaksimal mungkin dari hulu hingga ke hilir. Karena semua tidak hanya menjadi tanggung jawab terhadap peserta didik atau sekolah, melainkan akan menjadi tanggung jawab sepenuhnya terhadap Allah SWT

\section{DAFTAR RUJUKAN}

Ali, H.B. Hamdani. 1990. Filsafat Pendidikan. Yogyakarta: Kota Kembang.

Danim, Sudarwan. 2003. Agenda Pembaruan Sistem Pendidikan. Yogyakarta: Pustaka Pelajar.
Firdaus, LN. 2010, Powerful the Points of Guru, Pekanbaru, UNRI Pres.

Jalaluddin dan Usman Said. 1994. Filsafat Pendidikan Islam: Konsep dan Perkembangan Pemikirannya. Jakarta: PT Radja Grafindo Persada.

Mulyasa, E. 2004. Kurikulum Berbasis Kompetensi: Konsep, Karakteristik, dan Implementasi (cet ke 6). Bandung: PT Remadja Rosda Karya.

Prayitno. 2008. Dasar Teori dan Praksis Pendidikan. Padang: Universitas Negeri Padang.

Prayitno. 2009. Dasar Teori dan Praksis Pendidikan. Jakarta: Gramedia Jakarta

Prayitno, 2010, Modul, Pendidik Profesional, Universitas Negeri Padang

Prayitno, 2011, Profesi Pendidik, Padang : Universitas Negeri Padang.

Prayitno, 2011. Makalah"Membangun Filsafat dan Ilmu Pendidikan" UNP Padang

Sidi, Indra Djati. 2001. Menuju Masyarakat Belajar: Menggagas Paradigma Baru Pendidikan. Jakarta: Paramadina

Suhartono, Suparlan. 2006. Filsafat Pendidikan. Jogjakarta: Ar-Ruzz.

Suriasumantri, Jujun. S. 2003. Filsafat Ilmu: Sebuah Pengantar Populer. Jakarta: Pustaka Sinar Harapan.

Tilaar, H.A.R. 2004. Paradigma Pendidikan Nasional (cet kedua). Jakarta: Rineka Cipta.

Undang-undang RI No. 20 Tahun 2003 tentang Sisdiknas. Jakarta

Undang-undang RI No. 14 Tahun 2005 tentang Guru dan Dosen. Jakarta

Uno, Hamzah B. 2007. Profesi Kependidikan. Jakarta: Bumi Aksara. 